\title{
On the Function of Reading Aloud Classic Literature in Ideological and Political Education
}

\author{
Ke Zhang \\ Guangdong Polytechnic Normal University, No. 293 Zhongshan Avenue West, Tianhe District, \\ Guangzhou \\ 421084376@qq.com
}

Keywords: Reading aloud classics; Ideological and political education; Functionality; Cultural TV show

\begin{abstract}
A host of popular cultural TV shows such as Readers, Letters Alive, and Trust in China have prompted crowds of Chinese people to set their eyes on reading aloud classic literature. Through these TV shows, the ideological attribute, patriotism, images and allusions, and diversified themes embedded in the classics have been recognized as working on the ideological and political education targeted at the public. It is concluded that the roles reading aloud classics plays in the ideological and political education may be brought into full play from the following four dimensions: theoretical guide, inheritance of classics, cultural illustration, and media transmission, with a view to enhancing the artistic quality and practical efficiency of the ideological and political education.

Set in particular times, literary classics could indicate some political complexion, bear an abundance of humanistic connotations, pass on the fine traditional Chinese culture, and embody the scientific views towards the world, life and value, thus serving as an important way to promote the ideological and political education. Reading aloud classics represents an artistic form which could facilitate the spread of aesthetics contained in literature and art by marrying literary works with the magic of reading out, so as to transmit aesthetic connotations of the ideological and political education. It is therefore to say that reading aloud classics not just casts light on how to tap further functions of the ideological and political education but means a lot to the artistic research in such education.
\end{abstract}

\section{Literary classics and reading these classics aloud}

Literary classics are time-honored literary works that enjoy widespread popularity even in today's world. Being original, exemplary and authentic, these literature works reveal impressive value in aesthetics, representation and perfection. Some typical examples in this regard are the Book of Songs, the first collection of ancient Chinese poetry, and A Dream of Red Mansions, the peak of Chinese classical novels. Literary classics are different from Marxist classics. Classic works of Marxism stand as the direct source of contents used in the ideological and political education. Therefore, they are of fundamental and primary significance. By contract, literary classics contain ideological attribute, patriotism, images and allusions, and diversified themes. They play implicit roles in the ideological and political education, by providing it with indirect resources. In this sense, they are of promotional and auxiliary significance.

Reading aloud is a creative activity through which textual words can be transformed into verbal language. It comes in two types: the one is reading texts out loud directly; the other is an art of articulate speech through recreation. Both readers and audiences can attain a sense of aesthetic enjoyment from this form of art. In the verbal language, the most prominent aesthetic characteristics is rhythmic beauty, which finds concrete expression in many vocalization skills including voiced/unvoiced pronunciation, tone variations, sihu (four types of finals), resonance, alliteration (adjacent syllables having the same initial), vowel rhyme, allophonic variations, zero tone, and erhua (rhoticalizaton). Besides, the charm of verbal language also can be reflected through many expression techniques such as clear semantics, sincere emotion, mellow and delicate voice, and vivid linguistic performance. Reading aloud literary classics means a process through which people 
after fully perceiving, comprehending or appreciating the contents and connotations of literature works read them aloud with appropriate emotions. It emphasizes that readers must take their subjective initiative for recreation. Literary classics possess enormous vitality to go beyond a variety of spatial and temporal borders, usually representing the result of human wisdom. Therefore, reading aloud literary classics is in essence to pass on and spread these works. The reason for such cultural TV shows as Readers, Letters Alive, and Trust in China make a hit lies in that they precisely locate the connecting point between literature works and the outpouring of people's emotions. In other words, they manage to strike a chord with crowds of people. Reading aloud Marxist classics is aimed to advocate reading out classic works of Marxism loud. It comes as a campaign that directly involves every aspect of the ideological and political education. The primary difference between reading aloud literary classics and reading aloud Marxist classics lies in aesthetical characteristics contained in the former. Therefore, reading aloud literary classics is expected to work on the ideological and political education in a subtly penetrating way.

\section{The roles of literary classics in the ideological and political education}

Literary classics which stand out as conscious, independent essences of art enjoyable to the entire society are aimed to educate, influence and guide people to understand and transform the world. Ideological and political education that works on people is expected to foster humans who are well-developed morally, intellectually, physically and artistically. In such a context, literary classics remain consistent with the ideological and political education in their ultimate goals. Thus, these classic works could contribute positively to the education on political ideology.

Ideological attribute embedded in literary classics could add an aesthetical touch to ideological education. Literature, functioning as a form of ideology, needs to express itself through classic works. Classic literature works demonstrate both the prevailing attributes of general ideology and the particular attributes of aesthetical ideology. According to Marx's historical materialism, the structure of a society is composed of economic base and superstructure. As Marx argued, "on the economic base is a whole superstructure of different and characteristic feelings, illusions, ways of thinking and views of life."[1] Thus it can be seen that "Superstructure stands as a sum of various systems, feelings, beliefs, illusions, ways of thinking, and world views that are affected and restricted by economic base. It is made up of various ideological forms including law, politics, religion, art, and philosophy."[2] Literature, an artistic form of language, holds an essence of "the form of ideology". It is a general way of literature to express its ideology. In addition, literature is more of an aesthetical ideology. Classic literature works, specific literary language systems made up of different linguistic units like words, phrases, sentences, paragraphs, and chapters, are in the final analysis aimed to reproduce the complicated social life scenes through imagination. Therefore, the aesthetical ideology embedded in literary classics means a process through which aesthetical expressions and different ideologies in such works influence and penetrate into each other. Aesthetical ideas built of textual language are inextricably interwoven with ideologies, so that the latter can find their subtle expression. This can be specifically embodied in the fact that literary classics, despite being non-utilitarian, could vividly expose the utilitarian nature of the society as a blend of passion and rationality.

Ideological education, mainly dealing with world views and methodologies, is focused on reconciling subjectivity with objectivity. The key in such education rests on teaching people scientific theories with which they will withstand the sway of wrong trends of thought, develop rational world views, views of life, and values, and help to consolidate the dominant role of proletariat and socialist ideologies. In this sense, ideological education is a process of compulsorily political inculcation to some extent. Classic literature works demonstrate both the prevailing attributes of general ideology and the particular attributes of aesthetical ideology. The aesthetical attributes are direct or explicit while the social attributes are indirect or implicit. Therefore, literary classics always do well in hiding or penetrating social intentions in an aesthetical world of literary expressions. By reading these works, people receive ideological education unconsciously. In this way, ideological education turns itself into an artistic and aesthetical process. 
Patriotism embedded in literary classics could help to soften political education. Patriotism has been the main theme of literature works since the very beginning of their appearance. Authors often pour their care for the fate of the state into literary classics. Many pieces of persuasive evidence in this respect can be found in countless classical literature works, which include Sorrow after Departure by Qu Yuan, Three Officials and Three Farewells by Du Fu, a famous poetry line by Wang Anshi which reads "plan and worry ahead of people", and one oft-cited poetry line of Wen Tianxiang, who put it as "Everyone must die, let me but leave a loyal heart shining in the pages of history". In modern literature works, such examples are varied from the quotation by Liang Qichao which goes as "If the youth are strong, society will be strong; if the youth are independent, society will be independent" to the citing of Lin Zexu, which has it that "I will do whatever it takes to serve my country even at the cost of my own life, regardless of fortune or misfortune to myself." When it comes to contemporary literature, $\mathrm{Lu} \mathrm{Xu}$ ever wrote the well-known poetry line which reads "Fierce-browed, I coolly defy a thousand pointing fingers; head-bowed, like a willing ox I serve the children"; Xia Minghan willingly died, chanting "Beheading does not matter, as long as the true doctrine"; Shu Ting composed the famous poem entitled "My Homeland, My Dear Homeland"; and Ai Qing devoted his touching patriotism to a poet named "I Love This Land". All these patriotism-laden classic works shine with a compelling artistic appeal, capable of arousing patriotic feelings out of readers anytime, anywhere.

Political education is dedicated to teaching people with correct political ideals, beliefs, directions, stances, ideas, emotions, methods, and disciplines among other things, so that they can build up patriotism, collectivism and socialism in their mind, and increase their political consensus and emotional bonds with the Party, motherland and socialism. Converting patriotic literary classics into political education materials for subtly spiritual edification and patriotism enhancement proves to be far more concrete and persuasive than expounding the significance of patriotism mechanically. So it is fair to say that patriotic sentiments contained in literary classics could help to soften the blunt political education.

Images and allusions created in literary classics could make moral education more emotional. Literary images are concrete and perceptual pictures of landscape and life that authors create to embody their artistic taste, aesthetical ideal, and aesthetical value. Literary allusions are stories or legends about historical figures, ancient laws and regulations that appear in literary works. Literary images and allusions constitute a dispensable part of literary classics. Typical literary images and allusions not only possess eternal artistic charm, but also have great bearing on readers. An array of leading characters who deliver a presence of being selfless, fearless, aspiring, and enterprising can be found in countless literary classics throughout different phases of literature development. There are two examples in classical literature works. The one is the gentleman image Mencius advocates by depicting "Neither riches nor honors can corrupt him; neither poverty nor humbleness can make him swerve from principle; and neither threats nor forces can subdue him"; the other is Zhuge Liang, a famous figure in the Romance of the Three Kingdom, with the lofty pursuit that "stresses to give his best until his heart creases". Three examples in modern literature circles are Song of Youth, The Red Rock, and Tracks in the Snowy Forest. And another three examples in contemporary literature community are I am the Sun, Paramount Interest, and Choice.

Moral education is mainly committed to teaching people with codes of conduct and codes of ethics so that they can develop correct moral ideas, judgments, emotions, and attainments. It is made up of education campaigns on socialist morals, social morals, professional ethics, and family morals. The primary task of moral education is to internalize codes of ethics among people, so that they can practice these codes, guide and restrict their conducts with such codes, and develop moral self-discipline for stable moral conformity. Literary classics abound with characters typical of noble virtues and aspiring attitudes toward life as well as allusions spreading codes of ethics, hence providing adequate role models as needed by moral education campaigns. Therefore, citing vivid allusions of literary classics as role models can shift moral education from empty lecturing to fresh, touching narration, hence facilitating the ultimate realization of moral education. 
Diversified themes discussed in literary classics could make psychological education more rational. Various literary themes contribute to the diversity of literature works. Common themes in literature include love, kinship, friendship, war, martial arts, natural landscape, and trivia. Thanks to these varied themes, literature becomes a great emotional outlet and supplement. People can choose corresponding themes of literary classics to read to satisfy their psychological needs. Engels ever pointed out that "The popular book has the task of cheering, reviving and entertaining the peasant when he returns home in the evening tired from his hard day's work, making him forget his toil, transforming his stony field into a fragrant rose garden; it has the task of turning the craftsman's workshop and the wretched apprentice's miserable attic into a world of poetry, a golden palace, and showing him his sturdy sweetheart in the guise of a beautiful princess."[3] Therefore, when coming across setbacks in their love life, people may empathize with some sad yet beautiful love stories depicted in literary works. Take Liang Shanbo and Zhu Yingtai in Butterfly Lovers and Jia Baoyu and Lin Daiyu in A Dream of Red Mansions as two typical examples.

Psychological education is mainly dedicated to helping people improve their mental health. By providing psychological training and guidance, people will gradually develop good personality, sound character, optimistic mentality and tough willpower. In the face of difficulties, in particular, they are expected to forge ahead fearless of failures and setbacks and pursue for self-improvement and self-reliance. With various themes, literary classics can always provide people with something right to their appetite, whether they need additional impetus to remain positive and kind, or they are longing for some spiritual comfort or compensation. Reading fine literature works does good to the balanced development of human body and mind. Therefore, people often resort to literary classics to ease their mental conflicts and calm themselves down. In this way, literature works can propel psychological education towards rationality.

\section{Roles reading aloud literary classics plays in developing the functions of the ideological and political education.}

"The functions of ideological and political education can be mainly seen in the following four aspects: guide, guarantee, cultivation and development. These functions serve as an epitome of the ideological and political education in essence."'[4] Reading aloud literary classics plays significant roles in developing the functions of ideological and political education.

Bringing the guiding function out of the ideological and political education. Guiding function, as an embodiment of purpose and nature of the ideological and political education, constitutes the basic function of the education. It finds concrete expressions in guidance through ideal/faith, objective, and way of act.

Reading aloud literary classics can help to develop the guiding role of the ideological and political education. While reading the Sorrow after Departure out loud, people will harbor an ideal or a faith which has it "Endless is the road ahead, I shall pursue the truth by all means". Chanting aloud poems created by Tang and Song poets, readers can experience the compelling ambition and fearless encouragement as depicted in the poetry lines: "Difficult as conditions are, one should still refuse to give up", and "You can enjoy a grander sight by climbing to a greater height". Reading aloud such modern poetry lines as "I use my damaged palm to feel this vast land" and "Why are teardrops always welled in my eyes? Because I'm deeply in love with this land", offers a great chance to feel the overwhelming patriotism. In our opinion, often reading literary classics aloud can expose people to the correct ideals, faiths and codes of conducts, the patriotic sentiments, as well as the fine traditional Chinese culture embodied through the core socialist values. Guided by the fine culture, they are able to teach, improve and develop themselves consciously.

Bringing the assuring function out of the ideological and political education. Assuring function, a manifestation of the law that the ideological and political education is subordinated to and serves social development, proves to be an important function of the ideological and political education. With this function, people can keep their political mindsets and daily actions on the right track, thus helping to maintain political order and making it politically and ideologically possible to achieve social progress and human development. 
Likewise, reading literary classics also intensifies the assuring function. Reading Confucian classics such as the Four Books and the Five Classics is a great way to explore the appeal of traditional Chinese culture, and to gain an insight into the ancient thinkers' reflections on society, life and humanity. Inspired by these great classic works, people may learn the art of being a decent man and doing things right, elevate the aesthetical attainment and personal cultivation, and build up the well-developed character. Take Nostalgia a piece of modern poem as another case in point. As the last line of the poem reads, "My homesickness is a shallow strait, I am here, the mainland is there." While reading it, people can easily feel the strong wish of the poet for the reunification of the Chinese nation. Reading aloud these literature works gives moral education and etiquette education a shot in the arm, just as a spring breeze brings a much-wanted rain. It amplifies the assuring function of the ideological and political education.

Bringing the cultivating function out of the ideological and political education. Cultivating function of the ideological and political education needs to be realized through elevating the ideological and political attainment among people. This function proves to be an application of the laws that underlie the formation of ideologies and virtues as well as a basic feature of ideological and political education. Its ultimate purpose is to foster well-developed humans. Reading literary classics aloud help humans develop morally, intellectually and aesthetically. In doing so, people can enhance their ideological and political literacy as well as proficiency in scientific and cultural disciplines. Reading aloud many myths and legends such as the Foolish Old Man who removed the mountains, Jingwei Reclamation which is about a mythical bird trying to fill up the sea with pebbles, and Kuafu Chasing the Sun, people may have a close-up experience of the national ethos emphasizing ceaseless self-improvement as well as the persevering fight against nature obstacles. While reading aloud literature works that are developed around the revolutionary culture like The Red Rock and Song of Youth, people can comprehend the mighty strength of faith and dedication. Reading aloud some well-acclaimed literary classics that hail the advanced socialist culture including Tracks in the Snowy Forest and The Ordinary World, people will be impressed by the superiority of socialism and socialist culture, thus building up confidence in their own culture step by step. Reading aloud inspirational literary classics such as Strings of Life by Shi Tiesheng and Three Days to See by Helen Keller, they may appreciate the appeal of human nature in ceaseless pursuit of the true, good and beautiful.

Bringing the developing function out of the ideological and political education. Developing function of the ideological and political education is to get the most initiative and potential out of humans through the ideological and political education. This function can be seen as an extension of the abovementioned cultivating function. Apart from working on the ideological and political education, reading aloud literary classics is itself an artistic activity through which literature works are converted into verbal language for recreation and re-expression. Reading aloud stands out as a practice that generates both physical and spiritual benefits. According to types of literary classics, personality development of readers, and varying comprehensions of these works, people try to add a touch of musical, pictorial or performing appeal to the activity of reading aloud, making it a more aesthetical process. This is another embodiment of the developing function. To read, comprehend and recite literary classics, people need to take their initiative, bring their talent and expertise into full play, and arouse their enthusiasm and creativity, thus exploiting their intelligence and competence overall.

\section{Approaches to realize the ideological and political education function of reading aloud literary classics.}

Literary classics play an explicitly contributing role in the ideological and political education through an implicit method. Reading aloud literary classics can positively work on the ideological and political education from multiple perspectives. Therefore, importance shall be attached to the role reading aloud literary classics plays in the ideological and political education. With people placed at the center, we should enhance such role from four dimensions: theoretical guide, inheritance of classics, cultural illustration, and media transmission. On this basis, we can turn the 
ideological and political education into a campaign which enjoys considerable room, reveals great artistry, and generates real effect.

Marxist literary theory: catering to political needs of people. According to the Marxist literary theory, literature must be "a cog and a screw"[5] of the great mechanism of the Party, and become part of the undertakings of the Party. Putting people at the core serves as the fundamental principle of Marist literary theory. As Xi Jinping, President of China, noted at the artist symposium, "socialist literature belongs to people in essence."[6] Upholding the leading role of Marxist literary theory and basing their works on the needs of ordinary people make it possible for reading aloud literary classics to work on the ideological and political education. Reading literary classics aloud represents a type of artistic activity through which verbal language is used to reproduce literature works, by making the ideals/faiths, patriotism, moral virtues, and inner feelings embedded in such works heard clearly. While producing artistic works, artists should earnestly follow the leadership of the Party, practice the tenet of serving people, and try their best to increase their political identification and meet their political needs. In doing so, literature is well positioned to work on the ideological and political education, a contributing factor to the all-round development of humans.

Inheritance of classics: kindling people's emotional flames. The appeal of literary classics lies in the profound sense of history and the enriched emotional factors contained thereof. Every piece of literary classics must have survived the scrutiny of the lapse of time. The reason for them to do so is that they brim with emotional strength shared by the entire mankind. Such might serves as the plainest bond that connects people together. As Lenin ever pointed out that "the pursuit to truth would never be possible without the "feelings of human being'."[7] Given these considerations, China unveils a project entitled "Chinese Classical Texts Reading". The campaign of reading aloud literary classics is aimed to put this project in place, so that classic works can be passed on from generation to generation and keep nurturing people's inner world and educating them from the ideological, moral, political and psychological aspects. As more material and cultural progresses are being achieved and the pace of life are becoming faster, more people are addicted to fragmented or rough reading. Against such a backdrop, settling down to read some literary classics thoroughly all over again has practical bearing on inheriting these classics, igniting people's emotional flames, and promoting the ideological and political education in a subtly penetrating way.

Cultural illustration: arousing people's moral empathy. The reason for such TV shows as Readers, Letters Alive, and Trust in China gain so much popularity in the country is that people find spiritual satisfaction, mental pleasance and moral belongingness in reading aloud literary classics. Reading aloud classic works functions as an effective approach to teaching people with fine traditional Chinese culture. On one hand, it will revive the reading culture, making a wide range of literary works from songs of Chu, poems of Tang and Song and verses of Yuan, to modern and contemporary poems, to prose works, to novel fragments being memorized and chanted on everyone's lips. On the other hand, historical allusions, cultural customs, codes of ethics, thoughts and emotions contained in literary classics will be rendered to the life through the activity of reading aloud, with a view to fully revealing the charm of fine traditional Chinese culture, arousing the moral empathy among people, and throwing more light on the nature, purpose and significance of the ideological and political education.

Media transmission: inspiring people to engage in spiritual dialogue. Reading aloud literary classics can be seen on some extent as a spiritual dialogue between readers and fine literature works. Dialogues may come in various forms. However, no matter how changeable the forms are, the spiritual bonds always remain there without any change. Therefore, we should make good use of "Internet Plus" platforms and emerging media to support people in coming up with more creative approaches to reading literary classics aloud. For instance, audio clips may be recorded to make the practice of reading literature works more popular and influential. Besides, many TV shows including Readers, Letters Alive and Trust in China will be used to get more people involved in the reading aloud campaign, and to have a spiritual dialogue with these literary classics. On this basis, literature will facilitate the ideological and political education in the following multiple aspects: allowing it to exploit functions better, providing it with more potential opportunities for further 
development, adding an artistic touch to it, and empowering it to generate more real effect.

\section{References}

[1] Marx/Engels Collected Works (Volume I) [M]. Beijing: People's Publishing House, 1995, P611.

[2] Q.B.Tong, Course of Literary Theory (Version V) [M]. Beijing: Higher Education Press, 2015, P64.

[3] Marx/Engels Collected Works (Volume XLI) [M]. Beijing: People's Publishing House, 1972, P14.

[4] Y.C.Zhang,et al. Discipline of Modern Ideological and Political Education [M]. Beijing: People's Publishing House, 2006, P130.

[5] Collected Works of Lenin (Volume I) [M]. Beijing: People's Publishing House, 2012, P633.

[6] Speech of Xi Jinping at the Artist Symposium [M]. Beijing: People's Publishing House, 2015

[7] Collected Works of Lenin (Volume XXV) [M]. Beijing: People's Publishing House, 1988, P117. 